\title{
Body Mass Index and Gestational Weight Gain Are Associated with Maternal and Neonatal Outcomes Based on Chinese Women
}

\author{
Tingzhao Wang $\mathbb{D},{ }^{1,2}$ Lichun Li $\mathbb{D},{ }^{2}$ Chunchun Wu $\mathbb{D},{ }^{2}$ Rong Cao $\mathbb{D}^{2}$ Qingli Li $\mathbb{D}{ }^{2}$ Liji Yu $\mathbb{D}, 2$ \\ and Youguo Chen ${ }^{1}{ }^{1}$ \\ ${ }^{1}$ Department of Obstetrics and Gynecology, The First Affiliated Hospital of Soochow University, Suzhou 215006, China \\ ${ }^{2}$ Department of Obstetrics and Gynecology, Quanzhou First Hospital Affiliated to Fujian Medical University, \\ Quanzhou 362000, China
}

Correspondence should be addressed to Youguo Chen; chenyouguo@suda.edu.cn

Received 16 September 2021; Revised 5 November 2021; Accepted 8 November 2021; Published 24 November 2021

Academic Editor: Eusebio Chiefari

Copyright (c) 2021 Tingzhao Wang et al. This is an open access article distributed under the Creative Commons Attribution License, which permits unrestricted use, distribution, and reproduction in any medium, provided the original work is properly cited.

\begin{abstract}
The objective of the study is to analyze the association between early pregnancy body mass index (BMI), gestational weight gain (GWG), and maternal and neonatal outcomes. The retrospective cohort study was conducted at Quanzhou First Hospital Affiliated to Fujian Medical University from January 2018 to May 2021, with 552 women enrolled. Women were divided into the underweight group, normal weight group, overweight group, and obese group according to early pregnancy BMI. Univariate and multivariate logistic regression analyses were performed. The absolute risk of adverse maternal and neonatal outcomes in the early pregnancy BMI group was calculated to further analyze the association between GWG and adverse maternal and neonatal outcomes. Of the 552 women, 390 (70.65\%) women had adverse maternal and neonatal outcomes. The result revealed that overweight was associated with increased risk of adverse maternal and neonatal outcomes (odds ratio (OR): 1.643, 95\% confidence interval (CI): 1.006-2.684), maternal complications (OR: 1.937, 95\% CI: 1.188-3.159), and large for gestational age (LGA) (OR: 1.905, 95\% CI: 1.061-3.422). In the obese group, the risk of adverse maternal and neonatal outcomes (OR: 5.760, 95\% CI: 1.997-16.786), maternal complications (OR: 3.112, 95\% CI: 1.645-5.887), gestational diabetes mellitus (GDM) (OR: 2.943, 95\% CI: 1.509-5.741), cesarean section (OR: 1.899, 95\% CI: 1.002-3.599), and preterm delivery (OR: 4.752, 95\% CI: 1.395-16.185) increased. Besides, there was an association between insufficient GWG and decreased risk of LGA (OR: 0.392, 95\% CI: 0.187-0.826) and higher risk of preterm delivery (OR: 2.818, 95\% CI: 1.171-6.784). This study demonstrates that BMI and GWG are related to maternal and neonatal outcomes. It is necessary to regularly monitor the weight of pregnant women during pregnancy. And regional guidelines for GWG also need to be explored.
\end{abstract}

\section{Introduction}

In recent years, the prevalence of overweight and obesity among women at reproductive age is increasing $[1,2]$. The 2011 Pregnancy Nutrition Surveillance on maternal health indicators showed a prevalence of $4.5 \%$ and $53.7 \%$ of women having a prepregnancy body mass index (BMI) in the underweight and overweight category, respectively [3]. In China, the national nutrition survey revealed that being overweight and obese for women aged $18-44$ reached $21.8 \%$ and $6.1 \%$, respectively, and that there was an increasing trend particularly in women of childbearing age [4]. Being overweight or obese increases the risk of diabetes, high blood pressure, and disorders of fetal growth and is even linked to the development of many cancers, which is a serious global public health challenge [5]. The repercussion of this rising increase in weight on maternal and neonatal outcomes is imperative to be studied.

Previous studies have revealed that maternal outcomes are related to obesity in pregnant women, including gestational diabetes mellitus (GDM), pregnancy-induced hypertension, 
preeclampsia, and postpartum hemorrhage [6-8]. Nevertheless, studies examining the effect of pregnant woman's BMI on the neonatal and parturition outcome are scanty. The relationship between BMI and maternal and neonatal outcomes has not been fully studied. Pregnancy weight status may affect the total gestational weight gain (GWG), which is defined as weight just before delivery minus weight just before conception [9]. GWG reflects a variety of characteristics, including the accumulation of maternal fat, fluid swelling, and the growth of the fetus, placenta, and uterus [10]. GWG is necessary to ensure fetal health, but a study found that excessive GWG was associated with adverse outcomes [11]. Currently, most of the evidence on GWG values comes from Western or high-income countries $[12,13]$. The maternal and perinatal outcomes of GWG in developing countries still need to be elucidated. It is of particular relevance to study the effects of BMI and GWG on pregnancy and the newborn and to develop a reasonable pregnancy weight control plan.

The principal purpose of this study was to examine the effect of two anthropometric indicators (BMI and GWG) on maternal and neonatal outcomes in a sample of Chinese women. Besides, we calculated the absolute risk of adverse maternal and infant outcomes for GWG in the early pregnancy BMI to further analyze the association of GWG with maternal and neonatal adverse outcomes. This study may provide a reference for regular weight monitoring during pregnancy, appropriate weight gain during pregnancy, and solutions to reduce adverse maternal and neonatal outcomes.

\section{Methods}

2.1. Study Design and Participants. This study was a retrospective cohort study. We retrospectively collected data from 552 singleton pregnancies in the Quanzhou First Hospital Affiliated to Fujian Medical University from January 2018 to May 2021. The inclusion criteria were as follows: (1) women with singleton pregnancy and (2) regular postnatal examinations. Exclusion criteria were as follows: (1) women with chronic hypertension or pregestational diabetes; (2) women with previous pregnancy complications; (3) height $<140 \mathrm{~cm}$; (4) early pregnancy weight $<35 \mathrm{~kg}$; (5) gestation $<22$ weeks or $>44$ weeks; and (6) fetal malformations, fetal reduction, or fetal chromosomal abnormalities.

2.2. Data Collection. Data in this study were obtained from computer tracking systems or medical records, including (1) sociodemographic data: age (year) and education level; (2) adverse maternal outcomes: maternal complications including GDM, gestational hypertension, proteinuria, thrombocytopenia, impaired liver function, preeclampsia, placenta previa, chorioamnionitis, and parturition outcome (cesarean delivery); and (3) adverse neonatal outcomes: premature delivery, large for gestational age (LGA), small for gestational age (SGA), more than $48 \mathrm{~h}$ in the neonatal intensive care unit (NICU), Apgar score $<8$, and other neonatal complications.

2.3. BMI and GWG. All participants were weighed at $12 \pm 1$ weeks of gestation and were categorized into four subgroups by the range of BMI according to the WHO classifications: underweight (BMI $<18.5 \mathrm{~kg} / \mathrm{m}^{2}$ ), normal (BMI $18.5-25 \mathrm{~kg} /$ $\mathrm{m}^{2}$ ), overweight (BMI $\left.25-30 \mathrm{~kg} / \mathrm{m}^{2}\right)$, and obese $\left(\mathrm{BMI} \geq 30 \mathrm{~kg} / \mathrm{m}^{2}\right)$ [14].

GWG was defined as the difference between the final body weight before delivery and the prepregnancy body weight of mothers. GWG was further categorized into three subgroups according to the Institute of Medicine (IOM) [15] guidelines of recommended weight gain during pregnancy as inadequate, within the range, or excessive compared to the recommendations for different BMI categories (underweight: $12.5-18 \mathrm{~kg}$; normal weight: $11.5-16 \mathrm{~kg}$; overweight: 7-11.5 kg; and obese: $5-9 \mathrm{~kg}$ ) [14].

2.4. Adverse Maternal and Neonatal Outcomes. The main outcome of the analysis is the composite of any adverse outcome, which was defined as the presence of at least one of the following outcomes: GDM, gestational hypertension, preeclampsia, eclampsia, placenta previa, chorioamnionitis, cesarean delivery, premature delivery, LGA, SGA, more than $48 \mathrm{~h}$ in NICU, Apgar score $<8$, and other neonatal complications. The definition of preterm birth is less than 37 weeks of gestational age at birth. Use the Nordic reference chart to calculate gender-adjusted birth weight and age-adjusted SD score during pregnancy. SGA at birth was defined as genderand gestational age-adjusted birth weight less than 10th and greater than 90th percentile [11]. LGA was referred to a weight above the 90th percentile for gestational age [16].

2.5. Statistical Analysis. The measurement data of normal distribution were described as mean \pm standard deviation (mean \pm SD), and analysis of variance (ANOVA) was used for comparison between groups. Nonnormal distribution was exhibited as $M\left(Q_{1}, Q_{3}\right)$, and the Kruskal-Wallis $H$ rank sum test was used for comparison between groups. Enumeration data were described in terms of the number of cases and composition ratio $(N(\%))$. The chi-square test or Fisher's exact probability method was used for comparison between groups. The risk estimation was reported as an odds ratio (OR) with $95 \%$ confidence interval (95\% CI). Variables that had statistical significance in univariate analysis and had influence on maternal and neonatal adverse outcomes obtained from literature were included in multivariate logistic regression analysis to explore the influence of BMI in early pregnancy and GWG on maternal and neonatal adverse outcomes. The absolute risk of adverse maternal and neonatal outcomes in the early pregnancy BMI group was calculated to further analyze the association between GWG and adverse maternal and neonatal outcomes. All statistical tests were conducted by the two-tailed test, and $P<$ 0.05 was considered statistically significant. All statistical analyses were conducted using SAS Statistical Software version 9.4 (SAS Institute, Cary, NC, USA).

\section{Results}

3.1. Basic Characteristics of Included Pregnant Women. A total of 552 singleton women were included in this study, with an average age of $29.70 \pm 4.42$ years. In the early weeks of pregnancy, 120 (21.74\%) women were underweight, 209 
(37.86\%) women were normal weight, 164 (29.71\%) women were overweight, and 59 (10.69\%) women were obese. During pregnancy, 140 women $(25.36 \%)$ had insufficient GWG, 253 women (45.83\%) had suitable GWG, and 159 women (28.80\%) had excessive GWG. Fourteen women $(2.54 \%)$ had a history of premature birth, 205 (37.14\%) had a history of miscarriage, and 27 (4.89\%) had a history of medication. Adverse maternal and neonatal outcomes occurred in 390 (70.65\%) women, 277 (50.18\%) had cesarean delivery, and 328 (64.86\%) had neonatal adverse outcomes. Basic characteristics of the included population are shown in Table 1.

3.2. Comparison of Related Characteristics of Maternal BMI Groups in Early Pregnancy. The analysis results showed that the age $(F=15.377, P<0.001)$, the number of pregnancies $\left(\chi^{2}=20.350, P<0.001\right)$, the abortion history $\left(\chi^{2}=19.032\right.$, $P<0.001)$, the medication history $\left(\chi^{2}=11.295, P=0.010\right)$, the maternal complications $\left(\chi^{2}=22.224, P<0.001\right)$, the cesarean section $\left(\chi^{2}=28.799, P<0.001\right)$, the adverse neonatal outcomes $\left(\chi^{2}=32.349, P<0.001\right)$, and the adverse maternal and neonatal outcomes $\left(\chi^{2}=36.274, P<0.001\right)$ of the four groups were different, and the difference is statistically significant (Table 2).

3.3. Effects of BMI in Early Pregnancy on Maternal and Neonatal Adverse Outcomes. The result showed that underweight women had a reduced risk of adverse maternal and neonatal outcomes (OR: 0.616, 95\% CI: 0.388-0.975) and a reduced risk of cesarean section delivery (OR: 0.525, 95\% CI: 0.329-0.839) compared with normal weight women. Compared with women in the normal weight group, overweight women had an increased risk of adverse maternal and neonatal outcomes (OR: 1.926, 95\% CI: 1.198-3.094), maternal complications (OR: 2.140, 95\% CI: 1.329-3.446), cesarean section (OR: 1.618, 95\% CI: 1.070-2.448), and LGA (OR: 2.230, 95\% CI: 1.271-3.912). Similarly, obesity women had an increased risk of adverse maternal and neonatal outcomes (OR: 6.924, 95\% CI: 2.411-19.883), maternal complications (OR: 3.678, 95\% CI: 1.980-6.832), GDM (OR: 3.534, 95\% CI: 1.855-6.733), cesarean section (OR: 2.294, 95\% CI: 1.247-4.222), LGA (OR: 2.293, 95\% CI: $1.095-$ 4.802 ), and preterm birth (OR: 3.268, 95\% CI: 1.054-10.132).

After adjusting for age, history of miscarriage, number of pregnancies, and medication history, overweight women had an increased risk of adverse maternal and neonatal outcomes (OR: 1.643, 95\% CI: 1.006-2.684), an increased risk of maternal complications (OR: 1.937, 95\% CI: 1.188-3.159), and an increased risk of having LGA infants (OR: 1.905, 95\% CI: 1.061-3.422). In the obese group, the risk of adverse maternal and neonatal outcomes (OR: 5.760, 95\% CI: 1.997-16.786), maternal complications (OR: 3.112, 95\% CI: 1.645-5.887), GDM (OR: 2.943, 95\% CI: 1.509-5.741), cesarean section (OR: 1.899, 95\% CI: 1.002-3.599), and preterm delivery (OR: 4.752, 95\% CI: 1.395-16.185) increased (Table 3).

3.4. Effects of GWG on Maternal and Neonatal Adverse Outcomes. The analysis results indicated that compared with women with appropriate GWG, women with insufficient
TABLE 1: Basic characteristics of the included population.

\begin{tabular}{|c|c|}
\hline Variables & $(\mathrm{n}=552)$ \\
\hline Age (year), mean $\pm \mathrm{SD}$ & $29.70 \pm 4.42$ \\
\hline \multicolumn{2}{|l|}{ Early pregnancy BMI groups $\left(\mathrm{kg} / \mathrm{m}^{2}\right), n(\%)$} \\
\hline Underweight $(\mathrm{BMI}<18.5)$ & $120(21.74)$ \\
\hline Normal weight $(18.5 \leq \mathrm{BMI}<23)$ & $209(37.86)$ \\
\hline Overweight $(23 \leq \mathrm{BMI}<27.5)$ & $164(29.71)$ \\
\hline Obesity (BMI $\geq 27.5)$ & $59(10.69)$ \\
\hline \multicolumn{2}{|l|}{ GWG (kg), $n(\%)$} \\
\hline Insufficient & $140(25.36)$ \\
\hline Suitable & $253(45.83)$ \\
\hline Excessive & $159(28.80)$ \\
\hline \multicolumn{2}{|l|}{ Educational level, $n(\%)$} \\
\hline Junior high school and below & $120(21.74)$ \\
\hline High school or vocational high school & $155(28.08)$ \\
\hline Graduate degree and above & $277(50.18)$ \\
\hline Number of pregnancies, $M\left(\mathrm{Q}_{1}, \mathrm{Q}_{3}\right)$ & $2(1,3)$ \\
\hline History of premature birth, $n(\%)$ & $14(2.54)$ \\
\hline History of miscarriage, $n(\%)$ & $205(37.14)$ \\
\hline History of medication, $n(\%)$ & $27(4.89)$ \\
\hline Maternal complications, $n(\%)$ & $147(26.63)$ \\
\hline GDM & $105(19.02)$ \\
\hline Pregnancy-induced hypertension & $6(1.09)$ \\
\hline Proteinuria & $1(0.18)$ \\
\hline Thrombocytopenia & $6(1.09)$ \\
\hline Impaired liver function & $2(0.36)$ \\
\hline Preeclampsia & $39(7.07)$ \\
\hline Placenta previa & $2(0.36)$ \\
\hline Chorioamnionitis & $5(0.91)$ \\
\hline Parturition outcome (cesarean delivery), $n(\%)$ & $277(50.18)$ \\
\hline Adverse neonatal outcome, $n(\%)$ & $358(64.86)$ \\
\hline Premature delivery & $28(5.07)$ \\
\hline LGA & $84(15.22)$ \\
\hline SGA & $39(7.07)$ \\
\hline In NICU more than $48 \mathrm{~h}$ & $21(3.80)$ \\
\hline \multicolumn{2}{|l|}{ Apgar score $<8$} \\
\hline $1 \mathrm{~min}$ & $13(2.36)$ \\
\hline $5 \mathrm{~min}$ & $3(0.45)$ \\
\hline $10 \mathrm{~min}$ & $1(0.18)$ \\
\hline Other neonatal complications & $63(11.41)$ \\
\hline
\end{tabular}

Notes: BMI: body mass index; GWG: gestational weight gain; GDM: gestational diabetes mellitus; LGA: large for gestational age; SGA: small for gestational age; NICU: neonatal intensive care unit.

GWG had a decreased risk of having LGA infants (OR: 0.426, 95\% CI: 0.205-0.884) and women with excessive GWG during pregnancy had an increased risk of cesarean delivery (OR: 1.522, 95\% CI: 1.020-2.270). After adjusting for the variables age, education level, and history of miscarriage, insufficient GWG was associated with the decreased risk of having LGA infants (OR: 0.392, 95\% CI: $0.187-$ 0.826 ) and increased risk of preterm birth (OR: $2.818,95 \%$ CI: 1.171-6.784) (Table 4). 
TABLE 2: Comparison of related characteristics of maternal BMI groups.

\begin{tabular}{|c|c|c|c|c|c|c|c|}
\hline \multirow[b]{2}{*}{ Variables } & \multicolumn{5}{|c|}{ Groups } & \multirow[b]{2}{*}{ Statistics } & \multirow[b]{2}{*}{$P$} \\
\hline & Total & $\begin{array}{l}\text { Underweight } \\
\quad(n=120)\end{array}$ & $\begin{array}{l}\text { Normal weight } \\
\qquad(n=209)\end{array}$ & $\begin{array}{l}\text { Overweight } \\
(n=164)\end{array}$ & $\begin{array}{l}\text { Obesity } \\
(n=59)\end{array}$ & & \\
\hline Age (year), mean $\pm S D$ & $29.70 \pm 4.42$ & $28.03 \pm 3.88$ & $29.18 \pm 4.13$ & $31.01 \pm 4.72$ & $31.36 \pm 4.08$ & $F=15.377$ & $<0.001$ \\
\hline Educational level, $n(\%)$ & & & & & & $\chi^{2}=9.009$ & 0.173 \\
\hline Junior high school and below & $120(21.74)$ & $18(15.00)$ & $41(19.62)$ & $47(28.66)$ & $14(23.73)$ & & \\
\hline $\begin{array}{l}\text { High school or vocational high } \\
\text { school }\end{array}$ & $155(28.08)$ & $37(30.83)$ & $57(27.27)$ & $44(26.83)$ & $17(28.81)$ & & \\
\hline Graduate degree and above & $277(50.18)$ & $65(54.17)$ & $111(53.11)$ & $73(44.51)$ & $28(47.46)$ & & \\
\hline Number of pregnancies, $M\left(Q_{1}, Q_{3}\right)$ & $2(1,3)$ & $1(1,2)$ & $2(1,3)$ & $2(1,3)$ & $2(2,3)$ & $\chi^{2}=20.350$ & $<0.001$ \\
\hline History of premature birth, $n(\%)$ & $14(2.54)$ & $3(2.50)$ & $5(2.39)$ & $4(2.44)$ & $2(3.39)$ & $\chi^{2}=0.198$ & 0.978 \\
\hline History of miscarriage, $n(\%)$ & $205(37.14)$ & $27(22.50)$ & $76(36.36)$ & $72(43.90)$ & $30(50.85)$ & $\chi^{2}=19.032$ & $<0.001$ \\
\hline History of medication, $n(\%)$ & $27(4.89)$ & $3(2.50)$ & $9(4.31)$ & $7(4.27)$ & $8(13.56)$ & $\chi^{2}=11.295$ & 0.010 \\
\hline \multicolumn{8}{|c|}{ Adverse maternal and neonatal outcomes } \\
\hline Maternal complication, $n(\%)$ & $147(26.63)$ & $27(22.50)$ & $39(18.66)$ & $54(32.93)$ & $27(45.76)$ & $\chi^{2}=22.224$ & $<0.001$ \\
\hline $\begin{array}{l}\text { Parturition outcome (cesarean } \\
\text { delivery), } n(\%)\end{array}$ & $277(50.18)$ & $39(32.50)$ & $100(47.85)$ & $98(59.76)$ & $40(67.80)$ & $\chi^{2}=28.799$ & $<0.001$ \\
\hline Adverse neonatal outcome, $n(\%)$ & $358(64.86)$ & $58(48.33)$ & $128(61.24)$ & $122(74.39)$ & $50(84.75)$ & $\chi^{2}=32.349$ & $<0.001$ \\
\hline $\begin{array}{l}\text { Adverse maternal and neonatal } \\
\text { outcomes, } n(\%)\end{array}$ & $390(70.65)$ & $66(55.00)$ & $139(66.51)$ & $130(79.27)$ & $55(93.22)$ & $\chi^{2}=36.274$ & $<0.001$ \\
\hline
\end{tabular}

3.5. Absolute Risk of Adverse Outcomes with GWG in the Early Pregnancy BMI Group. The result showed that among women categorized as underweight, the absolute risk of adverse maternal and neonatal outcomes increased from $48.57 \%$ for suitable GWG to $100 \%$ for excessive GWG and the absolute risk was highest for cesarean delivery (highest risk: $85.71 \%$ for excessive GWG). The absolute risk of adverse maternal and neonatal outcomes increased from $65.71 \%$ with insufficient GWG to $73.40 \%$ with appropriate GWG among women categorized as normal weight, and the absolute risk of preterm birth is lowest (lowest risk: $85.71 \%$ for suitable GWG). Among women categorized as overweight, the absolute risk of adverse maternal and neonatal outcomes increased from $72.73 \%$ with appropriate GWG to $83.54 \%$ with excessive GWG and the absolute risk of cesarean section was the highest (highest risk: $63.29 \%$ for excessive GWG). And the absolute risk of adverse maternal and neonatal outcomes decreased from $100 \%$ of underweight gain to $95.65 \%$ of overweight gain among obese women. Table 5 depicts the absolute risk of adverse outcomes with GWG in the early pregnancy BMI group.

\section{Discussion}

Contradictory results between early pregnancy BMI, GWG, and maternal and neonatal outcomes have occurred in many cases, and most studies were conducted in high-income countries. We examined the association between BMI, GWG, and maternal and neonatal outcomes based on Chinese populations. Our findings displayed that high maternal BMI was associated with increases in risk of pregnancy complications, LGA, GDM, cesarean section, and premature delivery. Besides, compared with women who gained suitable GWG during pregnancy, women who did not gain enough weight during pregnancy had a decreased risk of having LGA infants and had an increased risk of preterm birth. In addition, results from absolute risk indicated that women with suitable GWG in the normal weight group had a high risk of adverse maternal and neonatal outcomes.

In our findings, obesity and overweight increased the risk of adverse maternal and neonatal outcomes, including LGA, GDM, cesarean section, and premature delivery. A population-based cohort study of almost 1.6 million singleton deliveries in Sweden from 1992 through 2010 showed an increased risk for preterm infants in overweight and obese pregnant women [17]. In this study, overweight women had an increased risk of pregnancy complications and obese women had an increased risk of GDM. Yong et al. [18] revealed that overweight/obese was independently associated with the risk of GDM. We observed a growing association between BMI and LGA outcomes, which was supported by other studies [4, 19]. Nowak et al. [19] demonstrated that underweight women were less likely to have a SGA newborn while obese mothers had a higher risk of a LGA newborn. Obesity is characterized by inflammatory upregulation, which is associated with proinflammatory cytokines and adipokines and alterations of the hypothalamic-pituitary-adrenal axis, being responsible for releasing corticotrophin-releasing hormone [20, 21]. In high values, it is known as a risk factor for premature rupture of membranes, preterm delivery, eclampsia, and pregnancyinduced hypertension [17]. This may be the underlying mechanism that explains adverse maternal and child outcome risk in women with higher BMI. 
TABLE 3: BMI in early pregnancy on maternal and neonatal adverse outcomes.

\begin{tabular}{|c|c|c|c|c|c|}
\hline \multirow{2}{*}{ Outcomes } & \multirow{2}{*}{ Early pregnancy BMI } & \multicolumn{2}{|c|}{ Univariate analysis } & \multicolumn{2}{|c|}{ Multivariate analysis } \\
\hline & & OR (95\% CI) & $P$ & OR $(95 \% \mathrm{CI})$ & $P$ \\
\hline \multicolumn{6}{|c|}{ Adverse maternal and neonatal outcomes } \\
\hline \multicolumn{6}{|l|}{ Total } \\
\hline & Underweight & $0.616(0.388-0.975)$ & 0.039 & $0.691(0.429-1.112)$ & 0.128 \\
\hline & Normal weight & Ref & & Ref & \\
\hline & Overweight & $1.926(1.198-3.094)$ & 0.007 & $1.643(1.006-2.684)$ & 0.048 \\
\hline & Obesity & $6.924(2.411-19.883)$ & $<0.001$ & $5.760(1.977-16.786)$ & 0.001 \\
\hline \multicolumn{6}{|c|}{ Maternal complications } \\
\hline & Underweight & $1.266(0.729-2.198)$ & 0.403 & $1.395(0.795-2.446)$ & 0.246 \\
\hline & Normal weight & Ref & & Ref & \\
\hline & Overweight & $2.140(1.329-3.446)$ & 0.002 & $1.937(1.188-3.159)$ & 0.008 \\
\hline & Obesity & $3.678(1.980-6.832)$ & $<0.001$ & $3.112(1.645-5.887)$ & 0.001 \\
\hline \multicolumn{6}{|l|}{ GDM } \\
\hline & Underweight & $0.615(0.304-1.244)$ & 0.176 & $0.671(0.328-1.372)$ & 0.274 \\
\hline & Normal weight & Ref & & Ref & \\
\hline & Overweight & $1.668(0.989-2.814)$ & 0.055 & $1.467(0.855-2.516)$ & 0.164 \\
\hline & Obesity & $3.534(1.855-6.733)$ & $<0.001$ & $2.943(1.509-5.741)$ & 0.002 \\
\hline \multicolumn{6}{|c|}{ Parturition outcome } \\
\hline \multicolumn{6}{|c|}{ Cesarean delivery } \\
\hline & Underweight & $0.525(0.329-0.839)$ & 0.007 & $0.603(0.370-0.981)$ & 0.042 \\
\hline & Normal weight & Ref & & Ref & \\
\hline & Overweight & $1.618(1.070-2.448)$ & 0.023 & $1.312(0.848-2.028)$ & 0.183 \\
\hline & Obesity & $2.294(1.247-4.222)$ & 0.008 & $1.899(1.002-3.599)$ & 0.049 \\
\hline \multicolumn{6}{|c|}{ Adverse neonatal outcome } \\
\hline & Underweight & $0.843(0.511-1.391)$ & 0.503 & $0.883(0.528-1.475)$ & 0.634 \\
\hline & Normal weight & Ref & & Ref & \\
\hline & Overweight & $1.522(0.989-2.340)$ & 0.056 & $1.433(0.917-2.240)$ & 0.115 \\
\hline & Obesity & $1.481(0.812-2.700)$ & 0.201 & $1.258(0.671-2.359)$ & 0.474 \\
\hline \multicolumn{6}{|l|}{ LGA } \\
\hline & Underweight & $0.581(0.251-1.343)$ & 0.204 & $0.673(0.287-1.579)$ & 0.363 \\
\hline & Normal weight & Ref & & Ref & \\
\hline & Overweight & $2.230(1.271-3.912)$ & 0.005 & $1.905(1.061-3.422)$ & 0.031 \\
\hline & Obesity & $2.293(1.095-4.802)$ & 0.028 & $1.709(0.784-3.726)$ & 0.178 \\
\hline \multicolumn{6}{|c|}{ Premature delivery } \\
\hline & Underweight & $1.519(0.498-4.629)$ & 0.462 & $1.494(0.477-4.676)$ & 0.491 \\
\hline & Normal weight & Ref & & Ref & \\
\hline & Overweight & $1.676(0.610-4.599)$ & 0.316 & $2.512(0.838-7.529)$ & 0.100 \\
\hline & Obesity & $3.268(1.054-10.132)$ & 0.040 & $4.752(1.395-16.185)$ & 0.013 \\
\hline \multicolumn{6}{|c|}{ Other neonatal complications } \\
\hline & Underweight & $0.625(0.280-1.393)$ & 0.250 & $0.570(0.253-1.281)$ & 0.173 \\
\hline & Normal weight & Ref & & Ref & \\
\hline & Overweight & $1.257(0.682-2.320)$ & 0.464 & $1.418(0.756-2.659)$ & 0.277 \\
\hline & Obesity & $1.038(0.423-2.543)$ & 0.937 & $1.218(0.484-3.062)$ & 0.675 \\
\hline
\end{tabular}

Notes: multivariate analysis was adjusted for age, education level, history of miscarriage, number of pregnancies, and medication history. BMI: body mass index; GDM: gestational diabetes mellitus; LGA: large for gestational age; OR: odds ratio.

Compared with suitable GWG, insufficient GWG was associated with higher risk for preterm birth in our findings. Similarly, the result from a study [22] indicated that low GWG was associated with an increased risk of all subtypes of preterm birth compared with normal GWG, especially in early spontaneous preterm births, where the risk was doubled. Goldstein et al. noted that low GWG was a risk factor for preterm birth [23]. It is hypothesized that low GWG 
TABLE 4: Effects of GWG on maternal and neonatal adverse outcomes.

\begin{tabular}{|c|c|c|c|c|c|}
\hline \multirow{2}{*}{ Outcomes } & \multirow{2}{*}{ GWG } & \multicolumn{2}{|c|}{ Univariate analysis } & \multicolumn{2}{|c|}{ Multivariate analysis } \\
\hline & & OR $(95 \% \mathrm{CI})$ & $P$ & OR $(95 \% \mathrm{CI})$ & $P$ \\
\hline \multicolumn{6}{|c|}{ Adverse maternal and neonatal outcomes } \\
\hline \multicolumn{6}{|l|}{ Total } \\
\hline & Insufficient & $0.976(0.627-1.520)$ & 0.915 & $0.899(0.567-1.425)$ & 0.651 \\
\hline & Appropriate & Ref & & Ref & \\
\hline & Excessive & $1.525(0.969-2.399)$ & 0.068 & $1.497(0.937-2.393)$ & 0.091 \\
\hline \multicolumn{6}{|c|}{ Maternal complications } \\
\hline & Insufficient & $1.083(0.686-1.709)$ & 0.733 & $1.039(0.654-1.651)$ & 0.872 \\
\hline & Appropriate & Ref & & Ref & \\
\hline & Excessive & $0.765(0.482-1.215)$ & 0.257 & $0.737(0.461-1.179)$ & 0.203 \\
\hline \multicolumn{6}{|l|}{ GDM } \\
\hline & Insufficient & $1.444(0.875-2.383)$ & 0.151 & $1.393(0.836-2.320)$ & 0.203 \\
\hline & Appropriate & Ref & & Ref & \\
\hline & Excessive & $0.840(0.493-1.431)$ & 0.521 & $0.822(0.478-1.413)$ & 0.479 \\
\hline \multicolumn{6}{|c|}{ Parturition outcome } \\
\hline \multicolumn{6}{|c|}{ Cesarean delivery } \\
\hline & Insufficient & $0.961(0.635-1.453)$ & 0.849 & $0.886(0.573-1.371)$ & 0.588 \\
\hline & Appropriate & Ref & & Ref & \\
\hline & Excessive & $1.522(1.020-2.270)$ & 0.040 & $1.492(0.979-2.274)$ & 0.062 \\
\hline \multicolumn{6}{|c|}{ Adverse neonatal outcome } \\
\hline & Insufficient & $0.876(0.562-1.366)$ & 0.559 & $0.839(0.534-1.318)$ & 0.447 \\
\hline & Appropriate & Ref & & Ref & \\
\hline & Excessive & $1.045(0.688-1.588)$ & 0.836 & $1.060(0.692-1.622)$ & 0.790 \\
\hline \multicolumn{6}{|l|}{ LGA } \\
\hline & Insufficient & $0.426(0.205-0.884)$ & 0.022 & $0.392(0.187-0.826)$ & 0.014 \\
\hline & Appropriate & Ref & & Ref & \\
\hline & Excessive & $1.412(0.847-2.354)$ & 0.186 & $1.424(0.840-2.413)$ & 0.189 \\
\hline \multicolumn{6}{|c|}{ Premature delivery } \\
\hline & Insufficient & $2.252(0.981-5.171)$ & 0.056 & $2.818(1.171-6.784)$ & 0.021 \\
\hline & Appropriate & Ref & & Ref & \\
\hline & Excessive & $0.568(0.178-5.171)$ & 0.340 & $0.427(0.128-1.422)$ & 0.166 \\
\hline \multicolumn{6}{|c|}{ Other neonatal complications } \\
\hline & Insufficient & $0.796(0.08-1.552)$ & 0.503 & $0.805(0.411-1.577)$ & 0.527 \\
\hline & Appropriate & Ref & & Ref & \\
\hline & Excessive & $0.914(0.493-1.696)$ & 0.776 & $0.933(0.501-1.739)$ & 0.828 \\
\hline
\end{tabular}

Notes: multivariate analysis was adjusted for age, education level, and history of miscarriage. GWG: gestational weight gain; GDM: gestational diabetes mellitus; LGA: large for gestational age; OR: odds ratio.

contributes to preterm birth through deficiencies in microand macronutrients, which increase the risk of preterm birth [24]. Nonetheless, Silva et al. [25] demonstrated that the rate of GWG was associated with preterm birth risk depending on the initial BMI. Prepregnancy BMI might play an important role in the relationship between GWG and preterm birth. The single and combined effects of BMI and GWG on the risk of adverse maternal and neonatal outcomes should also be considered. In general, clinicians use the IOM guidelines to educate pregnant women about the best GWG recommendations for different BMI categories [26]. However, we found that normal weight women with suitable GWG had a high risk of adverse maternal and neonatal out- comes, suggesting that the use of GWG guidelines may need to be reconsidered for individual difference. Further study may also be needed to determine applicable guidelines for Chinese women.

The data were rigorously obtained from the computer tracking system or medical records, ensuring the accuracy of the study data. However, several limitations should be taken into consideration. Our study was limited by its observational, retrospective, and single-center design, and the findings may not be generalizable to all pregnant women. Future studies should enroll participants from other hospitals in order to take into consideration regional, educational, and social differences. 


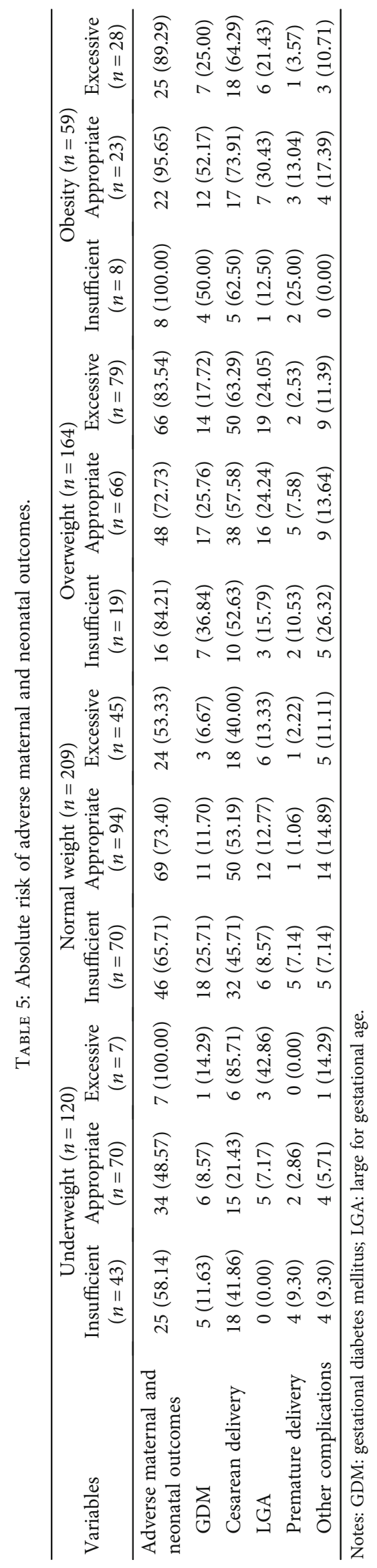




\section{Conclusions}

This study demonstrated that BMI and GWG were associated with adverse maternal and neonatal outcomes. In clinical practice, pregnant women should be instructed to have a clear understanding of weight gain, have regular examination during pregnancy, and reasonably control weight, reducing the risk of pregnancy complications and neonatal adverse outcomes.

\section{Data Availability}

No data are available for this manuscript.

\section{Conflicts of Interest}

The authors declare that there is no conflict of interest regarding the publication of this paper.

\section{Authors' Contributions}

Tingzhao Wang and Lichun Li are the coauthors.

\section{Acknowledgments}

This study was supported by the Startup Fund for Scientific Research, Fujian Medical University (Grant number 2020QH1269).

\section{References}

[1] L. Poston, R. Caleyachetty, S. Cnattingius et al., "Preconceptional and maternal obesity: epidemiology and health consequences," The Lancet Diabetes and Endocrinology, vol. 4, no. 12, pp. 1025-1036, 2016.

[2] I. Gonzalez-Ballano, R. Saviron-Cornudella, L. M. Esteban, G. Sanz, and S. Castán, "Pregestational body mass index, trimester-specific weight gain and total gestational weight gain: how do they influence perinatal outcomes?," The Journal of Maternal-Fetal \& Neonatal Medicine, vol. 34, no. 8, pp. 1207-1214, 2021.

[3] T. Papazian, G. Abi Tayeh, D. Sibai, H. Hout, I. Melki, and L. Rabbaa Khabbaz, "Impact of maternal body mass index and gestational weight gain on neonatal outcomes among healthy Middle-Eastern females," PLoS One, vol. 12, no. 7, article e0181255, 2017.

[4] Y. Sun, Z. Shen, Y. Zhan et al., "Effects of pre-pregnancy body mass index and gestational weight gain on maternal and infant complications," BMC Pregnancy and Childbirth, vol. 20, no. 1, p. 390, 2020.

[5] C. K. Yu, T. G. Teoh, and S. Robinson, "Obesity in pregnancy," BJOG: an international journal of obstetrics and gynaecology, vol. 113, no. 10, pp. 1117-1125, 2006.

[6] J. Ramachenderan, J. Bradford, and M. McLean, "Maternal obesity and pregnancy complications: a review," The Australian \& New Zealand Journal of Obstetrics \& Gynaecology, vol. 48, no. 3, pp. 228-235, 2008.

[7] K. Duckitt and D. Harrington, "Risk factors for pre-eclampsia at antenatal booking: systematic review of controlled studies," $B M J$, vol. 330, no. 7491, p. 565, 2005.
[8] A. S. Poobalan, L. S. Aucott, T. Gurung, W. C. Smith, and S. Bhattacharya, "Obesity as an independent risk factor for elective and emergency caesarean delivery in nulliparous women-systematic review and meta-analysis of cohort studies," Obesity Reviews, vol. 10, no. 1, pp. 28-35, 2009.

[9] Y. Liu, W. Dai, X. Dai, and Z. Li, "Prepregnancy body mass index and gestational weight gain with the outcome of pregnancy: a 13-year study of 292, 568 cases in China," Archives of Gynecology and Obstetrics, vol. 286, no. 4, pp. 905-911, 2012.

[10] R. Gaillard, "Maternal obesity during pregnancy and cardiovascular development and disease in the offspring," European Journal of Epidemiology, vol. 30, pp. 1141-1152, 2012.

[11] LifeCycle Project-Maternal Obesity and Childhood Outcomes Study Group, E. Voerman, S. Santos et al., "Association of gestational weight gain with adverse maternal and infant outcomes," JAMA, vol. 321, no. 17, pp. 1702-1715, 2019.

[12] S. A. Leonard, S. L. Carmichael, and B. Abrams, "Gestational weight gain and severe maternal morbidity at delivery hospitalization," Obstetrics and Gynecology, vol. 134, no. 2, p. 420, 2019.

[13] S. Santos, E. Voerman, P. Amiano et al., "Impact of maternal body mass index and gestational weight gain on pregnancy complications: an individual participant data meta-analysis of European, North American and Australian cohorts," British journal of obstetrics and gynaecology, vol. 126, no. 8, pp. 984995, 2019.

[14] Organization WH, "Obesity: Preventing and Managing the Global Epidemic," Report of a WHO Consultation, vol. 894 of WHO Technical Report Series, World Health Organization, Geneva, Switzerland, 2000.

[15] Sciences NAo, nutrition during pregnancy: part I, weight gain: part II, nutrient supplements, vol. 10, Natl Academy Pr, 1990.

[16] N. E. Stotland, A. B. Caughey, E. M. Breed, and G. J. Escobar, "Risk factors and obstetric complications associated with macrosomia," International Journal of Gynaecology and Obstetrics, vol. 87, no. 3, pp. 220-226, 2004.

[17] S. W. Masho, D. L. Bishop, and M. Munn, "Pre-pregnancy BMI and weight gain: where is the tipping point for preterm birth?," BMC Pregnancy and Childbirth, vol. 13, no. 1, p. 120, 2013.

[18] H. Y. Yong, Z. Mohd Shariff, B. N. Mohd Yusof et al., "Independent and combined effects of age, body mass index and gestational weight gain on the risk of gestational diabetes mellitus," Scientific Reports, vol. 10, no. 1, p. 8486, 2020.

[19] M. Nowak, M. Kalwa, P. Oleksy, K. Marszalek, M. Radon-Pokracka, and H. Huras, "The relationship between pre-pregnancy BMI, gestational weight gain and neonatal birth weight: a retrospective cohort study," Ginekologia Polska, vol. 90, no. 1, pp. 50-54, 2019.

[20] J. J. Reilly, J. Armstrong, A. R. Dorosty et al., "Early life risk factors for obesity in childhood: cohort study," BMJ, vol. 330, no. 7504, p. 1357, 2005.

[21] R. L. Goldenberg, J. F. Culhane, J. D. Iams, and R. Romero, "Epidemiology and causes of preterm birth," Lancet, vol. 371, no. 9606, pp. 75-84, 2008.

[22] E. A. Nohr, B. H. Bech, M. Vaeth, K. M. Rasmussen, T. B. Henriksen, and J. Olsen, "Obesity, gestational weight gain and preterm birth: a study within the Danish National Birth Cohort," Paediatric and Perinatal Epidemiology, vol. 21, no. 1, pp. 5-14, 2007. 
[23] R. F. Goldstein, S. K. Abell, S. Ranasinha et al., "Association of gestational weight gain with maternal and infant outcomes: a systematic review and meta-analysis," JAMA, vol. 317, no. 21, pp. 2207-2225, 2017.

[24] S. M. Eick, M. Welton, M. D. Claridy, S. G. Velasquez, N. Mallis, and J. F. Cordero, "Associations between gestational weight gain and preterm birth in Puerto Rico," BMC Pregnancy and Childbirth, vol. 20, no. 1, p. 599, 2020.

[25] Brazilian Multicenter Study on Preterm Birth (EMIP) study group, F. Pigatti Silva, R. T. Souza et al., "Role of body mass index and gestational weight gain on preterm birth and adverse perinatal outcomes," Scientific Reports, vol. 9, no. 1, p. 13093, 2019.

[26] R. F. Goldstein, S. K. Abell, S. Ranasinha et al., "Gestational weight gain across continents and ethnicity: systematic review and meta-analysis of maternal and infant outcomes in more than one million women," BMC Medicine, vol. 16, no. 1, p. 153, 2018. 